\title{
What's in a question? A Comparison of Student Questions in Two Learning Spaces
}

Julie Griffith

Ball State University, jgriffith2@bsu.edu

Mary Lou Vercellotti

Ball State University, mlvercellott@bsu.edu

Hannah Folkers

Ball State University, hbfolkers@bsu.edu

DOI: https://doi.org/10.30707/TLCSD3.1Griffith

Follow this and additional works at: https://ir.library.illinoisstate.edu/tlcsd

Part of the Speech Pathology and Audiology Commons

\section{Recommended Citation}

Griffith, Julie; Vercellotti, Mary Lou; and Folkers, Hannah (2019) "What's in a question? A Comparison of Student Questions in Two Learning Spaces," Teaching and Learning in Communication Sciences \& Disorders: Vol. 3: Iss. 1, Article 7. DOI: https://doi.org/10.30707/TLCSD3.1Griffith

Available at: https://ir.library.illinoisstate.edu/tlcsd/vol3/iss1/7

This Scholarship of Teaching and Learning Research is brought to you for free and open access by ISU ReD: Research and eData. It has been accepted for inclusion in Teaching and Learning in Communication Sciences \& Disorders by an authorized editor of ISU ReD: Research and eData. For more information, please contact ISUReD@ilstu.edu. 


\title{
What's in a question? A Comparison of Student Questions in Two Learning Spaces
}

\begin{abstract}
Active learning pedagogy is thought to allow more opportunities for student interaction. Given that students are more interactive, student questions may reveal how active learning pedagogy may enhance student learning outcomes. The purpose of this research was to investigate the frequency, distribution, and type of questions asked by students during class meetings in two instructional contexts: a traditional lecture classroom and an interactive learning space classroom. A neuroanatomy and neurophysiology for speech, language and hearing course was taught in the two spaces in subsequent semesters. A total of 99 enrolled students gave consent. Six 75-minute class meetings from each classroom were recorded; questions were transcribed, labeled for location and coded for depth: non-content, foundational knowledge, and application of knowledge questions. The results revealed that the frequency of student questions was similar in both spaces. However, the questions were more distributed in the interactive space. The highest proportion of questions posed were application questions in both spaces with more application questions in the traditional space but more non-content questions in the interactive space. Course design, immediacy, and student maturity may have influenced the types of questions observed. Instructors who implement active learning pedagogy may see more student engagement through questions.

\section{Keywords}

Interactive-learning, questions, learning spaces

\section{Cover Page Footnote}

Author Note Acknowledgements The authors would like to thank the Office of Educational Excellence at Ball State University for encouraging this collaboration. We would also like to thank all speech pathology and audiology students who participated in this study. Declaration of interest The authors report no conflicts of interest. The authors alone are responsible for the content and writing of this paper. Correspondence concerning this article should be addressed to: Julie Griffith, Ph.D. CCC-SLP, Department of Speech Pathology and Audiology, jgriffith2@bsu.edu, Mary Lou Vercellotti Ph.D., Department of English, and Hannah Folkers B. S., Department of Speech Pathology and Audiology, Ball State University, Muncie, IN.
\end{abstract}

This scholarship of teaching and learning research is available in Teaching and Learning in Communication Sciences \& Disorders: https://ir.library.illinoisstate.edu/tlcsd/vol3/iss1/7 


\section{Introduction}

Some universities have begun to explore the impact of learning spaces on student affect and learning outcomes. A motivation for teaching in interactive learning spaces (ILS) is that students have reported they prefer learning in ILS classrooms (Largent, Pierce, Stallings, \& Zimmermann, 2013) and some students show improved learning outcomes (Vercellotti, 2017). Yet, it is currently unclear how classroom interactions might differ in various classroom settings. Student questions posed to instructors are an observable behavior of student engagement. It is plausible that the frequency of students' questions may be influenced by classroom settings, which hinder or promote immediacy. This paper explores the interaction between classroom setting and student questions posed to the instructor during class meetings.

Active Learning. Professional clinicians are often not trained in teaching practice and are likely unfamiliar with student-centered pedagogy (Ginsberg, Friberg, \& Visconti, 2012). In fact, "many new faculty begin their teaching careers having little instruction on how to teach or what constitutes evidence-based education" (Ginsberg et al., 2012, p. 41). Recently, active learning has begun to replace traditional college teaching. Active learning is a broad term that refers to any activity in which students are personally engaged in the learning process by doing an activity and thinking/reflecting on that activity (Bonwell \& Eison, 1991). Learning science research has found that active, constructive, and interactive learning is more robust than passive learning in which students are solely listening (Chi, 2009). Bloom's Taxonomy (Bloom \& Krathwohl, 1956), a foundational pillar to evidence-based education, has suggested that students achieve higher levels of learning when the cognitive, affective, and psychomotor domains are stimulated. Accordingly, classroom teaching should foster forms of critical thinking specifically within the domains of cognition and affect to promote high levels of learning for students (Ginsberg et al., 2012). Therefore, active learning likely promotes student participation through reading, discussing, writing, building or creating to engage in higher levels of critical thinking.

Instructional Design. In order to encourage active learning and to engage students during class meetings, some instructors have changed the format of their courses. With "reverse" teaching (Nguyen, Yu, Japutra, Chen, 2016) or "flipped" classrooms (Kim, Kim, Khera \& Getman, 2014), the initial content delivery is done before the class meeting, which allows the class meeting time to be devoted to application of the course content. For instance, some instructors provide videos or podcasts for the students to watch as pre-class homework so that face-to-face class sessions can focus on other instructional activities (Bergmann \& Sams, 2009). This teaching model was recently explored by Vinney and Harvey (2017) in the field of communication sciences and disorders. The researchers examined the use of a "flipped" course design and found that the students believed the pre-course online modules facilitated their application knowledge.

Despite the theoretical support for a "flipped" course design, some scholarship of teaching and learning (SoTL) research has found not all students appreciate that course format. For instance, Baeten, Dochy, Struyven, Parmentier, and Vanderbruggen (2016) found that more students report a preference for instructor direction. Likewise, Vinney and Harvey (2017) reported that many students stated that they would like "more time with the content and immediate feedback from the instructors" (Vinney \& Harvey, 2017, p. 16). Accordingly, courses that have a mixed course design (with both content delivery and student-centered activities) may be most effective because it allows for some content delivery in person (when needed) as well as student-centered activities. This 
flexibility in course format, which has been labeled as "scrambled" design (Barnett, 2014) or "flexible learning" design (Gunn, McCormick, \& Honey, 2002), has been adopted by instructors who want to create an active learning course (Vercellotti, 2017). It should be noted, however, that Baeten et al. (2016) also found that the students who want to develop deep understanding of course concepts have a preference for constructive active learning (e.g., when students produce a tangible learning artifact) to synthesize information through cooperative learning. When describing the cognitive benefits of cooperative and interactive learning, Chi (2009) explained that substantial and meaningful pedagogical discussions with rich questions and responses can be instructor-led (instructional dialogue) or peer-to-peer (joint dialogues). It is clear from these studies that instructors utilize varied course designs and students' perceptions of ideal designs for learning are widely varied.

Space. Traditional university classrooms are well suited for lecture-based teaching, where efficiency of space results in tight rows of student seating to prioritize space efficiency and accommodate higher enrollment. Unfortunately, this means that students tend to be passive during instructor lectures, especially in courses with more students (Marback-Ad \& Sokolove, 2000). Also, instructors are often physically far from the students in traditional classrooms. The physical distance, often a byproduct of traditional classroom spaces, may hinder student engagement with the course concepts and with the instructor. For instance, students are less likely to ask questions in a large lecture but more likely to ask questions if the instructor is physically nearby (Nguyen et al., 2016). In addition to cognitive engagement, space can alter social engagement. Kim et al. (2014) reported that students recognized how flipped courses influence their social engagement, including interactions and positive affect. In their study of classroom interactions, Frisby and Martin (2010) found that student participation was positively correlated with rapport with the instructor and with other students. Overall, immediacy behaviors, such as movement around the classroom, are correlated with both affect and learning (Gorham, 1998).

Student Questions. Researchers have investigated questions posed by the instructor (Redfield \& Rousseau, 1981; Riegle, 1976) and found that higher-level cognitive questions support student learning (Redfield \& Rousseau, 1981). However, in order to understand student learning, it may be more relevant to investigate questions posed by the students. Questions reveal the current state of the student's conceptual knowledge (Woodward, 1992), and the act of formulating a question itself can facilitate understanding and remembering (Bean, 1985). The skill needed to generate application questions from Bloom's affective domain is responding. The process of responding requires students to first reflect on their internal thinking and then act on their thinking by questioning. For high-quality application questions, synthesis is needed, which requires learners to reflect on newly acquired knowledge, demonstrate comprehension by reorganizing known content to create new ideas, and then generate questions that will further their understanding. Therefore, students demonstrate active learning and engagement through the number and type of questions posed. Despite the value of question creation, few students ask questions during large lecture-based teaching (Marbach-Ad \& Sokolove, 2000). In traditional lecture courses, maybe only the most prepared, knowledgeable or outgoing students participate in this manner. In fact, some researchers (Nguyen et al., 2016) report that students are hesitant to ask questions during lectures. This reluctance is detrimental to learning because asking questions engages the student in active learning, and formulating questions beyond the conveyed content is a constructive learning activity (Chi, 2009). Harper, Etkina, and Lin (2003) found that the type of question asked by students, rather than the number of questions, correlated with learning outcomes. Also, Marbach-Ad and 
Sokolove (2000) have reported that student questions improved after a teaching intervention, but only for students taught in a cooperative active-learning pedagogy (as compared to students in a lecture-based class with the same intervention). Previous research has considered undergraduate student questions written after reading the textbook (Marbach-Ad \& Sokolove, 2000) and undergraduate written questions from a weekly journal activity (Harper et al., 2003), both elicited written questions, rather than authentic classroom interactions. Further, given that active learning pedagogy allows students more opportunities for interactions with each other and with the instructor (Lage, Platt, \& Treglia, 2000; Nguyen et al., 2016), it could also facilitate student engagement through questions. However, little is known about the questions students formulate and ask during class meetings in both traditional and active learning classrooms.

Purpose. The purpose of this comparative research study was to investigate the frequency, distribution, and type of questions asked by students in a neuroanatomy and neurophysiology course for speech, language and hearing during class meetings in two instructional contexts: a traditional lecture classroom and in an interactive learning space classroom.

\section{Method}

Participants. All students enrolled in a neuroanatomy and neurophysiology course at a Midwest public university were invited to participate in a study about the pedagogical influence of instructional space. All were speech-language pathology or audiology majors, with sophomore through graduate status. At this university, graduate students in the audiology program were required to take a neuroanatomy and neurophysiology course, which means graduate and undergraduate students were often enrolled in the same course. As an in vivo classroom research study, the researchers could not control or manipulate the students who enrolled in each course. Until the conclusion of the study when informed consent was obtained, the students were not aware that their questions would be investigated. In sum, 99 of 102 students enrolled in these courses gave consent for participation in this study. Participants were recruited across two academic semesters: In the fall semester, 56 students consented ( 2 males and 54 females). Of these 31 held graduate or senior status while 25 were juniors. In the spring semester, 43 students consented (5 males and 38 females). Of these, 10 held senior status while 22 were juniors and 11 were sophomores. The participants were asked to take a pre-course knowledge test of neuroanatomy and neurophysiology that was not part of their grade to determine their baseline content knowledge during the first week of the semester. The students' post-course knowledge was assessed with a comprehensive final exam. The student cohorts were similar in initial content knowledge and in post-course knowledge, as determined by $t$-tests on pretest and posttest scores. There was not a significant difference in the pre-test by classroom, $t=0.96, p=0.33$. Likewise, there was not a significant difference in the post-test by classroom, $t=0.10, p=0.91$. See Table 1 for a comparison of the students' demographics and relevant statistics. 
Table 1

Student Demographics of the Traditional Classroom and Interactive Learning Space

\begin{tabular}{|c|c|c|c|}
\hline & $\begin{array}{c}\text { Traditional } \\
\text { Classroom }\end{array}$ & $\begin{array}{c}\text { Interactive Learning } \\
\text { Space }\end{array}$ & t-Test Statistic \\
\hline $\begin{array}{c}\text { Total Number of } \\
\text { Students }\end{array}$ & 56 & 43 & \\
\hline Male, Female & 2,54 & 5,38 & \\
\hline Academic Rank & & 10 & \\
\hline Senior/Graduate & 31 & 22 & \\
\hline Junior & 25 & 11 & \\
\hline Sophomore & 0 & $M=36.79, S D=8.75$ & $t=0.96, p=0.33$ \\
\hline $\begin{array}{c}\text { Baseline Content } \\
\text { Knowledge }\end{array}$ & $M=34.96, S D=8.58$ & $M=91.53, S D=7.44$ & $t=0.10, p=0.91$ \\
\hline $\begin{array}{c}\text { Post-course } \\
\text { Knowledge }\end{array}$ & $M=91.68, S D=6.64$ & $M=10$ \\
\hline
\end{tabular}

Course and Classrooms. The course, neuroanatomy and neurophysiology for speech, language and hearing, was taught in subsequent sixteen-week semesters. The objectives of the course focused on understanding the organization and functioning of the nervous system and laying the groundwork for understanding the effects of localized damage and disease processes of the nervous system on human communication. The traditional classroom had nine rows of tiered fixed student seats; the instructor and students could only move around the outside of the rows. The interactive classroom had twelve tables of four, which the teacher could easily visit each students' tables via two pathways. (See Figures 1 and 2 for classroom schematics). The traditional classroom activities primarily included lectures and drawing/imaging worksheets to label structures of the brain and pathways of the nervous system. A flexible teaching course design was employed during the interactive learning space course, where some lectures and study materials were recorded and posted onto a learning management system to be reviewed prior to class meetings. The flexible teaching course design in an interactive learning space allowed students to have more time working with brain models and identifying nervous system structures on images, (e.g., computed tomography scans). See Table 2 for a summary of the pedagogical approaches utilized in each classroom.

Table 2

Summary of the Pedagogical Approaches

\begin{tabular}{|l|l|l|}
\hline \multicolumn{1}{|c|}{ Student Activities } & \multicolumn{1}{|c|}{ Traditional } & \multicolumn{1}{c|}{ Interactive Learning Space } \\
\hline $\begin{array}{l}\text { Students } \\
\text { Class Preparation }\end{array}$ & Reading text book & Reading textbook and watching videos \\
\hline $\begin{array}{l}\text { Students' } \\
\text { Participation During } \\
\text { Class Meetings }\end{array}$ & $\begin{array}{l}\text { Listening to lecture, } \\
\text { completing individual } \\
\text { worksheets }\end{array}$ & $\begin{array}{l}\text { Listening to lecture, working in groups } \\
\text { including worksheets, presentations and } \\
\text { manipulating brain models, identifying } \\
\text { nervous system structures on computed } \\
\text { technology and magnetic resonance } \\
\text { imaging studies }\end{array}$ \\
\hline
\end{tabular}


Observations and Coding. Six 75-minute class meetings were audio recorded in each classroom, for a total of 12 observations, with one observation approximately every three weeks throughout the semesters with a Sony HD video recorder HDRCX405 Handycam. Specifically, the same lectures and topics were recorded in each space and included: a) gross structures of the brain, b) brainstem and ventricles, c) action potentials, d) vascularization, e) auditory system and d) cranial nerves. All student questions were tallied (frequency) and labeled for location with schematics of each classroom in real-time by members of the research team to capture the distribution of questions posed. The questions in each recording were transcribed verbatim and verified. The questions were then coded into three prior determined questions types (Redfield \& Rousseau, 1981) and included: 1) non-content 2) foundational knowledge, and 3) application knowledge. Student questions were coded as foundational knowledge if the question asked for declarative knowledge or clarification of information. For instance, one student asked, "Where is the premotor cortex?" after the professor had given the information. Student questions were coded as application questions if the question focused on applying course information to physiology. One student, for instance asked "Is the premotor cortex involved in initiating movement?" The foundational knowledge and application knowledge question types correspond to "lower" and "higher" level cognitive questions (Redfield \& Rousseau, 1981). Although foundational knowledge and application knowledge questions are, of course, most closely tied to learning, noncontent questions also demonstrate investment in the course, so these questions were not excluded. A non-content category has been used in other SoTL research (Vercellotti, 2017) as a measure of student engagement. See appendix for further description and examples of each question type.

Reliability. Cohen's Kappa was calculated to determine interrater reliability between two members of the research team on $50 \%$ of the coded questions. A kappa of 0.741 or $87 \%$ reliability was found which is indicative of substantial agreement (Landis \& Koch, 1977). Any disagreements noted were discussed amongst the research team until consensus was reached across raters.

\section{Results}

Frequency and Type of Questions. In the traditional classroom, the 56 students asked a total of 54 questions during the six observed class meetings, for a ratio of 0.96 questions per student. Of the 54 questions, $5(9 \%)$ were non-content, $16(30 \%)$ were foundational, and $33(61 \%)$ were application. During the six observed class meetings in the interactive classroom, the 43 students asked a total of 43 questions for a ratio of 1.0 question per student where 14 (33\%) were noncontent, $13(30 \%)$ were foundational, and 16 (37\%) were application. See Table 3 for a visual comparison of the number and types of questions raised by the students in the two classroom spaces.

Table 3

Frequency of Questions by Type and Classroom

\begin{tabular}{|l|c|c|}
\hline \multicolumn{1}{|c|}{ Question Type } & Traditional Classroom & $\begin{array}{c}\text { Interactive Learning } \\
\text { Space }\end{array}$ \\
\hline Non-content & $5(9 \%)$ & $14(33 \%)$ \\
\hline Foundational Knowledge & $16(30 \%)$ & $13(30 \%)$ \\
\hline Application Knowledge & $33(61 \%)$ & $16(37 \%)$ \\
\hline Total & 54 & 43 \\
\hline
\end{tabular}


Distribution. In the traditional class room, where nearly all the seats were filled, 14 students, $25 \%$, were responsible for asking 48 questions. The majority, 94\%, of the questions came from the first four rows and the remaining $6 \%$ of questions arose from students in the four rows which were the farthest away from the instructor podium (Figure 1). Six additional questions occurred after class at the teaching podium.

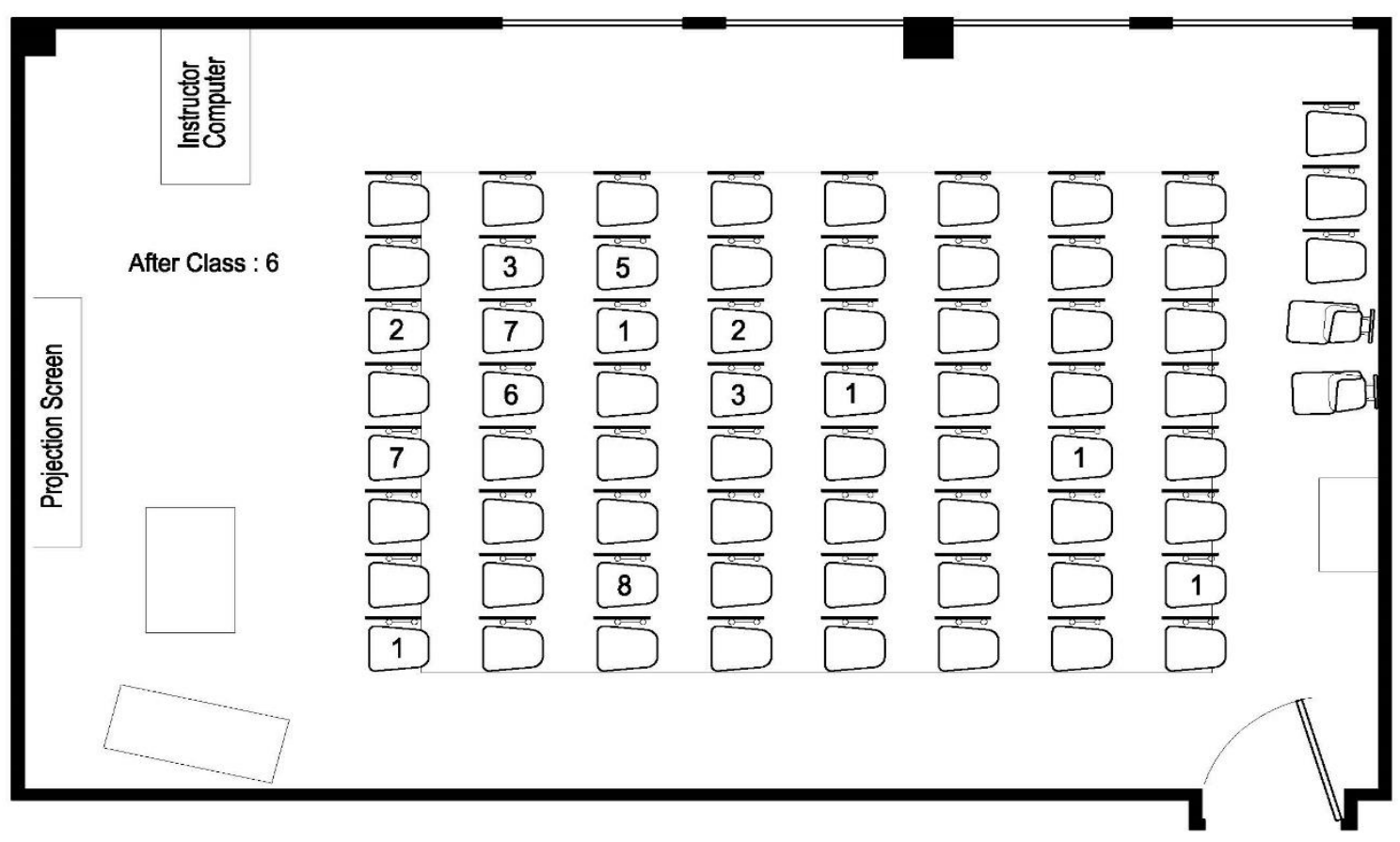

Figure 1. Distribution of Questions in Traditional Classroom

In the interactive learning space classroom, the number of enrolled students fell under the number of available seats. In that section, 20 students, $47 \%$, asked 43 questions. The majority, $76 \%$, of the questions came from the tables closest to the instructor's podium. The remaining $24 \%$ of questions were consistently distributed across the classroom and arose from students sitting at least one table away from the instructor. Five questions were raised at the end of the classroom session throughout the space (Figure 2). 


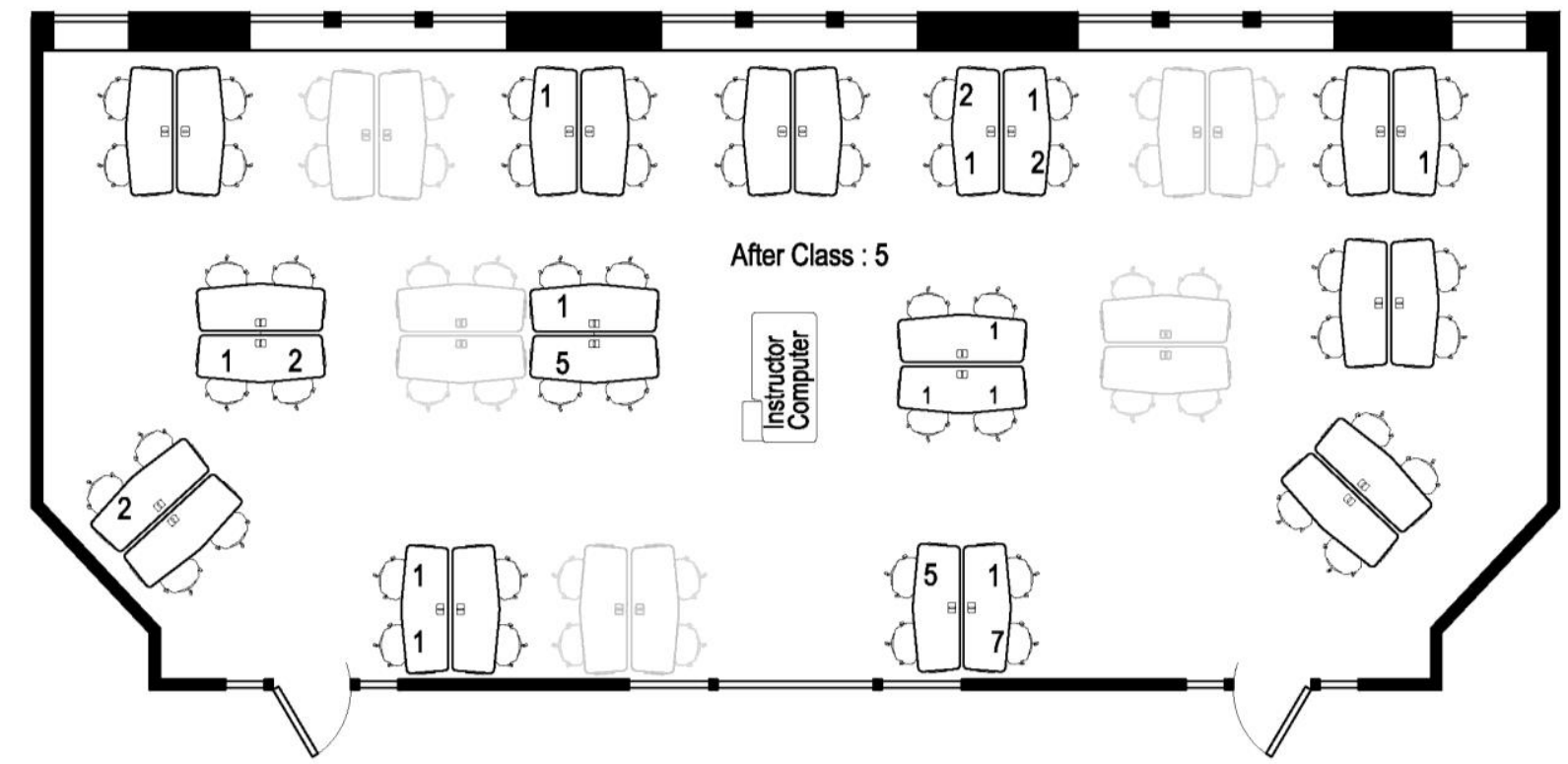

Figure 2. Distribution of Questions in an Interactive Learning Space Classroom

Note: Seats that remained empty for the entire semester were greyed out to indicate no student questions could have come from that location.

\section{Discussion}

The purpose of this research study was to investigate and compare the frequency, distribution, and type of questions asked by the students in a traditional and interactive learning space classroom. The results, as well as how the findings may impact classroom teaching, are discussed in the following sections.

Frequency. The students in both learning contexts posed questions to the instructor at similar rates. In fact, the ratio of students per questions was nearly identical, 0.96 per student in the traditional space and 1.0 per student in the interactive space. However, only $25 \%(n=14)$ of the students in the traditional space were responsible for the questions asked during class. During the class meetings held in the interactive learning space $47 \%(n=20)$ of students asked questions, nearly double the number of students who posed questions in the traditional classroom. Therefore, while the ratio of students per questions was consistent among the two types of classroom spaces, the interactive learning space prompted more students, approximately half, to participate in class by questioning the instructor.

Furthermore, it was informally noted that the assigned small group seating arrangement of the interactive learning space fostered more peer-to-peer questions than observed in the traditional space. It is likely that the layout of each of the classroom directly influenced the frequency of questions directed to the instructor during the observed sessions. For instance, the students in the interactive learning space may have had more questions, but chose to ask a peer instead of the instructor; and the students in the traditional space may have had more questions, but were hesitant to ask in front of the entire class, as reported by Nguyen et al. (2016). 
Type of Questions. The student questions were coded by the focus of the question.

Non-content. The students taught with the flexible teaching course design in the interactive learning space classroom asked more non-content clarification questions than the students in the traditional lecture. The increased use of technology and group activities could explain why the students in the interactive learning space classroom asked 24\% (Interactive Learning Space $=33 \%$, Traditional Classroom $=9 \%$ ) more non-content knowledge questions than those in the traditional classroom. There were many questions regarding how and when to access technology in the learning management system for assignments and quizzes as well as clarifying directions for the collaborative assignments. As stated, with the flexible teaching design, a potential drawback is that instructors spend less classroom time delivering content (lecturing) to allow students to have more time for collaborative learning activities. While many of the questions in the interactive classroom were not focused on content, the students' learning was not hindered as they had very similar postcourse content scores to the students in the traditional classroom.

Foundational Questions. Unlike ephemeral traditional lectures, the flexible teaching course design of the interactive learning space allowed students to have unlimited access to lectures and materials that covered foundational knowledge. The design also allowed for more in class time to be devoted to applying the foundational information to case studies typical of practicing audiologists and speech-language pathologists. Despite having access to recorded lectures and presentations, the students in both spaces asked foundational questions at the same rate, $30 \%$. The students most often asked foundational knowledge questions to verify their understanding of where nervous system structures were located and the function of those structures. It was informally observed that the students in the interactive learning space classroom tended to asked foundational questions not necessarily to learn new information but to verify that they had learned the material correctly.

Application Questions. Over half of the questions posed in the traditional learning space were application based, 61\%. This finding suggests that the students were eager to learn how this information relates to their future or current clients. Many of the students in the traditional space were seniors and graduate students who were serving clients in the on-campus speech and hearing clinic. Therefore, it is reasonable to assume that the students wanted to ask practical application questions about neurology that they could readily apply to their current clinical practice. The students in the interactive learning space were younger on average and only a few had senior status, which would allow them to be active in the on-campus speech and hearing clinic. That being said, the students in the interactive learning course still asked application questions with the highest frequency, 37\%. The high number of application questions in the traditional space could have been observed for a number of reasons. First, it is reasonable to believe that the age and academic status of the students influenced the type of questions asked. It is plausible that more senior students likely have learned how they learn and know when they need to ask questions. They also, through more years of college experience, may feel more comfortable approaching and asking questions of instructors, even without previous courses with specific instructors. Second, the senior and graduate status students displayed that they have learned critical thinking skills and are ready to apply classroom knowledge to real world clients through application questioning. Lastly, the traditional lecture design did not allow for as much classroom time to be devoted to the discussion of case studies and how exactly information could be applied to clients as in the interactive learning 
space's flexible teaching design. Bergmann and Sams (2009) reported that they spent more time "actively walking around the classroom, engaging students, checking for understanding, and augmenting the content with higher-order questioning" (p. 23) after adopting a flexible teaching course design in their chemistry class. Therefore, the students in the traditional space likely took it upon themselves to ask the tough application questions during class to take ownership of their own learning.

Distribution. It is thought that the configuration of seating and proximity of the instructor to the students influenced the distribution of questions. In both classrooms, the students who sat closest to the instructor's podium asked the majority of the questions. A staggering, $94 \%$ of questions came from the first few rows of the traditional stadium-seating style classroom in which the students self-selected their seats. Even more, only $25 \%$ of students in the traditional classroom posed questions while nearly double, $47 \%$, asked a question in the interactive learning space where the instructor could walk around the room and be close to each student, echoing conclusions of Marbach-Ad and Sokolove (2000). Therefore, the immediacy in the interactive learning space fostered more class participation from a greater number of students than the traditional space. This is congruent with previous research (Nguyen et al., 2016) which found that students in lectures are less likely to ask questions but more likely to ask questions if the instructor is nearby.

Limitations and Future Directions. Several pedagogical features changed when the course moved from a traditional classroom based course design to a flexible teaching course design which created unavoidable limitations in this investigation (as with most classroom research), such as the number and academic status of the students who enrolled in each course. In this exploratory study, three categories of questions were coded which may not have captured the true range and scope of the critical thinking and knowledge evidenced by the students' posed questions. Future investigations could code questions into more specific categories to capture a true hierarchy of learning. Also, this investigation only focused on student questions directed to the instructor and was unable to capture student-to-student questions. Given the increased positive affect and interactions in "flipped" and/or flexible teaching courses (Kim et al., 2014), future investigations could include peer-to-peer dialogue since grouped table seating promotes peer dialogues while row seating may discourage cooperative learning. Additionally, since instructor questions are a common teaching technique with most being knowledge-based (Riegle, 1976), instructors inadvertently model these types of questions. As a result, future research should consider the types of instructor's questions that are modeled for students. Of course, the instructor's elicitation and encouragement of and response to student questions (or lack thereof) should be considered, particularly the impact of an intervention to improve student questions. The influence of an intervention which encourages and scaffolds collaborative formation of application questions, such as bringing written questions to class for discussion (Harper et al., 2000; Tracy, 2017) on the type of questions posed, should be explored. This research investigated group behavior; forthcoming projects could investigate the questions of particular students, such as students with low pre-course knowledge to see how increased student activity and engagement might narrow the knowledge gap (Vercellotti, 2017). Additionally, a comparison of the amount of self-study and time spent reviewing posted lectures and material prior to class between traditional lecture style and flexible teaching course designs on learner questions and outcomes (Vercellotti \& Olsen, 2016) ought to be conducted. 


\section{Conclusions and Recommendations for Educators}

This investigation found the frequency of student questions to be similar in a traditional space and an interactive learning space classroom. A wider variety of students in the interactive space classroom asked questions, which is a sign of more students actively engaged in their learning. The students in the traditional classroom asked more application questions while questions that are more non-content were asked in the interactive space. Non-content questions could be diminished in the future by instructors setting aside 2-3 minutes per class to discuss course assignments, how to access technology and then follow up with posted announcements and emails. Doing this would make sure that face to face time is devoted to establishing foundational knowledge and encouraging application of course content. Furthermore, this study shows that instructors do not need to be concerned that incorporating active learning and collaborative student activities into course designs would hinder student learning outcomes. When instructors dare to implement active learning pedagogy, students will benefit from an increase in engagement with course material, better preparing students for clinical practice.

\section{References}

Baeten, M., Dochy, F., Struyven, K., Parmentier, E., \& Vanderbruggen, A. (2016). Studentcentered learning environments: An investigation into student teachers' instructional preferences and approaches to learning. Learning Environment Research, 19, 43-62.

Barnett, P. E. (2014). Let's scramble, not flip, the classroom. Inside Higher Ed, 14.

Bean, T. W. (1985). Classroom questioning strategies: Directions for applied research. In A.C. Graesser \& J. B. Black (Eds.), The psychology of questions (pp. 335-358). Hillsdale, NJ: Erlbaum.

Bergmann, J., \& Sams, A. (2009). Remixing chemistry class: Two Colorado teachers make vodcasts of their lectures to free up class time for hands-on activities. Learning \& Leading with Technology, 36(4), 22-27.

Bloom, B., \& Krathwohl, D. (1956). Taxonomy of educational objectives: The classification of educational goals. New York, NY: Longmans, Green, Co.

Bonwell, C. C., \& Eison, J. A. (1991). Active learning: Creating excitement in the classroom. Washington, DC: The George Washington University.

Chi, M. T. H. (2009). Active-constructive-interactive: A conceptual framework for differentiating learning activities. Topics in Cognitive Science, 1, 73-105.

Frisby, B. N., \& Martin, M. M. (2010). Instructor-student and student-student rapport in the classroom. Communication Education, 59, 146-164.

Ginsberg, S. M., Friberg, J. C. \& Visconti, C. F. (2012). Scholarship of teaching and learning in speech-language pathology and audiology: Evidence based education. San Diego, CA: Plural Publishing Inc.

Gorham, J. (1998). The relationship between verbal teacher immediacy behaviors and student learning. Communication Education, 37, 40-53.

Gunn, C., McCormick, R., \& Honey, M. L. (2002). The challenge of change: Introducing flexible learning into a traditional medical and health sciences faculty. Presentation at the 
ASCILITE conference. Retrieved from http://www.ascilite.org/conferences/auckland02/proceedings/papers/125.pdf

Harper, K. A., Etkina, E. \& Lin, Y. (2003). Encouraging and analyzing student questions in a large physics course: Meaningful patterns for instructors. Journal of Research in Science Teaching, 40(8), 776-791.

Kim, M. K., Kim, S. M., Khera, O., \& Getman, J. (2014). The experience of three flipped classrooms in an urban university: An exploration of design principles. The Internet and Higher Education, 22, 37-50.

Lage, M. J., Platt, G. J., \& Treglia, M. (2000). Inverting the classroom: A gateway to creating an inclusive learning environment. The Journal of Economic Education 31(1), 30-43.

Landis, J. R., \& Koch, G. G. (1977). The measurement of observer agreement for categorical data. Biometrics, 33, 159-174.

Largent, D., Pierce, R., Stallings, L., \& Zimmermann, P. (2013, November). Classroom Interaction Redefined: A multidisciplinary perspective on moving beyond traditional classroom spaces to promote student engagement. Poster presented at the Original Lilly Conference on College Teaching, Miami University, Oxford, OH.

Marbach-Ad, G., \& Sokolove, P. G. (2000). Can undergraduate biology students learn to ask higher level questions? Journal of Research in Science Teaching, 37(8), 854-870.

Nguyen, B., Yu, X., Japutra, A., \& Chen, C-H. S. (2016). Reverse teaching: Exploring student perceptions of "flip teaching." Active Learning in Higher Education, 17(1), 51-61.

Redfield, D. L \& Rousseau, E. W. (1981). A meta-analysis of experimental research on teacher questioning behavior. Review of Educational Research, 51(2), 237-245.

Riegle, R. P. (1976). Classifying classroom questions. Journal of Teacher Education, 27(2). 156161.

Tracy, R. (2017, October). A variation on active learning that promotes student learning and critical thinking. Poster presented at the 2017 Lilly Conference, Traverse City, MI.

Vercellotti, M. L. (2017). Do interactive learning spaces increase student achievement? A comparison of classroom context. Active Learning in Higher Education, Advance online publication. doi:10.1177/1469787417735606.

Vercellotti, M. L. \& Olsen, D. (2016, November). If you post it, will they read? An investigation of student activity in the learning management system for a flipped course. Paper presented at the 2016 Original Lilly Conference on College Teaching, Miami, OH.

Vinney, L. A. \& Harvey, J. M. T. (2017). Bridging the gap: An integrated approach to facilitating foundational learning of neuroanatomy and neurophysiology in graduate-level speech-language pathology coursework. Teaching and Learning in Communication Sciences and Disorders, 1(2), 1. Retrieved from https://ir.library.illinoisstate.edu/cgi/viewcontent.cgi?article=1005\&context=tlcsd

Woodward, C. (1992). Raising and answering questions in primary science: Some considerations. Evaluation and Research in Education, 6. 145-153. 


\section{Appendix}

Operational Definitions of Level of Questions

Application of Knowledge Question: These questions require the highest level of critical thinking and seek to understand how a nervous structure works or how it is involved in human functioning. They are primarily physiology based.

Example: Is the premotor cortex involved in initiating movement?

Foundational Knowledge Question: These questions require little critical thinking and seek to recall a specific idea or anatomic structure. They are often anatomy based.

Example: Where is the premotor cortex?

Non-content Questions: These questions require no critical thinking and seek information regarding classroom procedures, such as class schedule or how to turn in assignments.

Example: Is the quiz Thursday online or in class? 